\title{
GSM Based Energy Efficient Meter Reading System with Accounting
}

\author{
Antony Veera Puthira Raja $\mathbf{J}^{1}$ Vishalakshi $\mathrm{S}^{2}$ Vidhya $\mathrm{G}^{3}$ \\ Department of Electronics and Communication Engineering, \\ Vels Institute of Science, Technology \& Advanced Studies (VISTAS), Chennai. \\ E-Mail: antony.se@velsuniv.ac.in
}

\begin{abstract}
-
In recent technology of e-metering (electronic metering) has high developed in their advanced future for high performance with effective Automatic Meter Reading (AMR) framework. It represents modern structure with simple connection and minimal effort with wireless GSM energy meter which includes fault indication, unit usage alert (i.e. for 15 days once), mode selection (Automatic \& Manual) and SMS alert to the user. To avoid further consumption of energy, we are setting a limit for every house and if the limit exceeds methods are used to cut-down the appliances according to user convenience both automatically and manually. If there is fault in the e-meter it also sends a notification to the user. Electrically Erasable Programmable Read only Memory which is used for friendly modifiable Read only Memory which can make the data to be erased and reprogrammed using electrical voltage. The proposed system neglects regular meter reading system and allow remotely access the electronic meter (e-meter). The advantage of this project is to reduce the usage of energy and to reduce the cost, save more power and also reduce time consumption. This idea is implemented using the software ARUDINO IDE (using embedded C language).
\end{abstract}

Keywords: Automatic Meter Reading System (ARMS), GSM (Global System for Mobile Communication), RTC (Real Time Clock), Arudino IDE.

\section{INTRODUCTION}

The model has microcontroller ATMEGA328P, GSM module, LCD display, V/I controller, EEPROM, RTC. Microcontroller repeatedly monitors the emeter using the transmitter of GSM which transmit the data to the receiver. Accountable payments are done with late payment and use of more man-power can be overcome by AMRS system. People with more apartments and high class flats consumes more energy can be reduced by e-monitoring system. This model will send the bill statement through mobile network. Thus it is more useful for present situation. The increase in current source makes increase in power consumption. This paper power consumption can be minimized by proper usage of current source.

\section{LITERATURE SURVEY}

Where greatest request of vitality devours will be demonstrated in the meter utilized by the buyer. [2] Clarified subsequent to surpassing the most extreme request, the meter and henceforth the association will be naturally detached by an installed framework embedded in the meter itself. As indicated by the greatest request, the shopper will buy a money card of sum contingent upon the utilization of vitality and after the full utilization; the buyer once more has to buy another money card or revive the same and to remain in a long line and to present the bill can be evaded, which is utilized to disengage a line if the vitality utilization every day of a buyer enormously surpasses a pre-request vitality utilization every day.

The GAPMR (GSM Automatic Power Meter Reading System) is comprises of GSM advanced meter introduced in each buyer unit and a power e-charging framework at the vitality supplier side. [1] Explained SIM modem which use the GSM system to send its energy utilization perusing utilizing short informing frame work (SMS) back to the vitality supplier remotely. At the power supplier side an echarging framework is utilized to deal with every 
got Smart meter perusing, Compute the charging cost, refresh the database, and to distribute charging notice to its individual purchaser through SMS, email, web-based interface and printed postage mailing.

In LDR (Light Dependent Resistor) sensor programmed vitality meter perusing utilizing GSM module. [5] Explained a framework which measure current utilization unit through LDR sensor. The LDR sensor set on a vitality meter which sense LED flickering heartbeat. Around then microcontroller send this perusing by means of GSM module. GSM module sends this message to power board.

In this framework a keen vitality meter is introduced in each purchaser unit and a server is kept up at the specialist co-op side. [6] Explained both the meter and the server are outfitted with GSM module which encourages bidirectional correspondence between the two finishes utilizing the current GSM framework. Buyers can without much of a stretch energize their vitality meter by sending a PIN number covered up in a scratch card to the server utilizing SMS.

This idea gives a cost proficient and secure way of power charging. The present vitality charging frameworks are discrete, mistaken, expensive and moderate. The significant downside of conventional charging frameworks is to show the power and vitality utilization just in units so the customer gets befuddled about his power charge. [3] Explained this downside is diminished by utilizing shrewd power charging which depends on the idea

"Get your power charge in your money day by day". Here the framework will compute the bill sum as indicated by the present tax esteems and shows and send as SMS to the client. The data additionally gave to the power office and to the client utilizing GSM innovation for charge instalment reason.

\section{PROPOSED WORK OF GSM BASED ENERGY EFFICIENT METER}

The present arrangement of power charging is mistake level and furthermore tedious. Mistakes presented at each stage are expected to electro-mechanical meters, human blunders while taking note of down the meter perusing, mistakes while preparing the paid bills, and the due bills. Brilliant vitality meter is a strategy in which it can decrease the issues related with the charging and furthermore lessens the arrangement of labour for taking meter readings.

In addition with the existing system innovative to include an alert message to the user energy consumed for 15 days once, constant alert message with payment details and power usage until the payment is done. To avoid the further consumption of energy, we are setting a limit for every house and if the limit exceeds methods are used to cut-down the appliances according to user convenience both automatically and manually. If there is fault in the e-meter it also sends a notification to the user.

The proposed framework for the most part works in two-modes.

\section{Selecting the Mode:}

1. Automatic mode

In general there is a limit of unit usage for each and every house, office and etc... The unit limit is depends upon place and the mode of use to overcome the function of limit is fixed and price will increase according to the usage. To reduce this problem automatic mode is used. The usage is nearer to the limit fixed. GSM sends alert to the user or crossed to the limit automatically device will cut-off. Device is selected by the user convenience.

2. Manual mode

In this mode manually the switch is turned to manual mode from automatic mode. A mid manual mode the client can expended as much as it is required by the presence of customer known.

\subsection{PROBLEM ANALYSIS}

The power board have used to the manual procedure and they oblige it even however there are numerous worries related with it. On account of the human blunders in the wake 
of getting flawed bill,it is issue of client to get it remedied from the energy supply board. All things considered client needs to visit the office,stand in line and get it corrected.The issue is a direct result of human mediation. To stay away from human mediation in the charging process, in this new age a programmed perusing meter framework came into utilization.

To avoid the further consumption of energy, we are setting a limit for every house and if the limit exceeds methods are used to cut-down the appliances according to user convenience both automatically and manually. The system will monitor the EB meter reading periodically without reaching the home to note the reading. If there is any fault in e-meter it also sends a notification to the user. To reduce the usage of energy, save more power, time consumption and cost. Design and implement a system that will enable users to remotely control their home appliances through the internet and get feedback from the appliance. The existance and explained in the following figure (I).

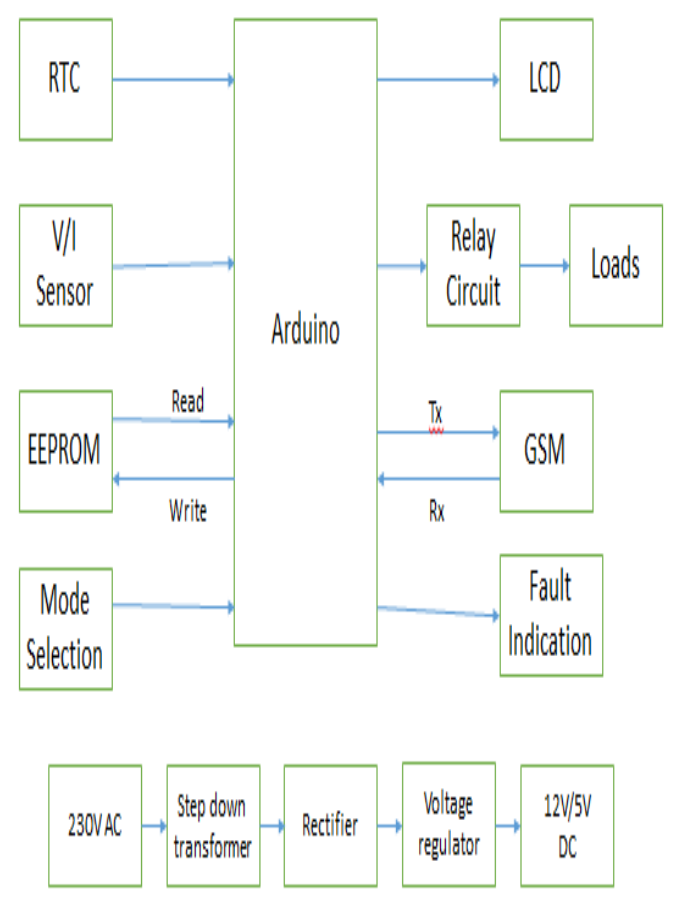

Fig (I) Block Diagram of e-Meter

\subsection{WORKING OF E-METER}

Watt hour meter or enrgy meter is an instrument which measures measure of electrical vitality utilized by customers. These instrument at each place like homes, industries,organizations to change the power utilization by burdens, for example, lights, fans and different machines.

Essential unit of energy is watts. One thousand watts is one kilowatt. On the off chance that we utilize one kilowatt in 60 minutes, it is considered as one unit of vitality devoured. These meters measure the prompt voltage and currents. This control is coordinated over a period which gives the vitality used over that day and age.

\section{RESULT}

\section{(i).AUTOMATIC MODE}

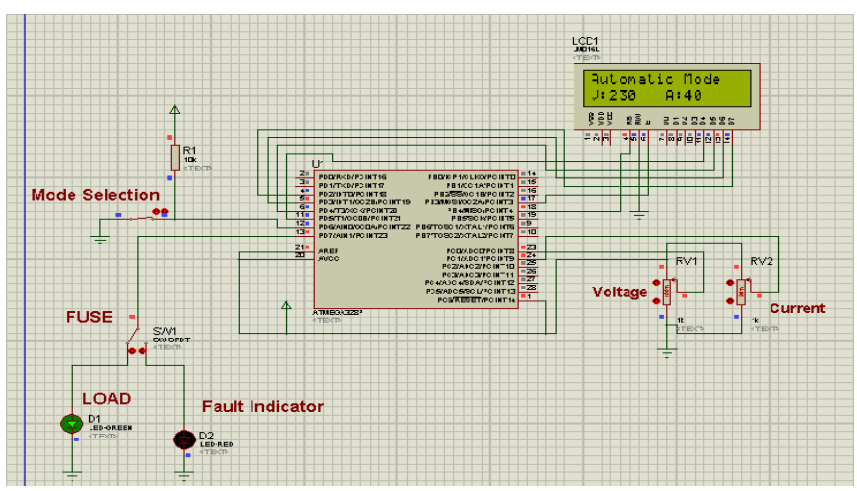

Fig(II) Output of Automatic Mode

\section{(ii). MANUAL MODE}

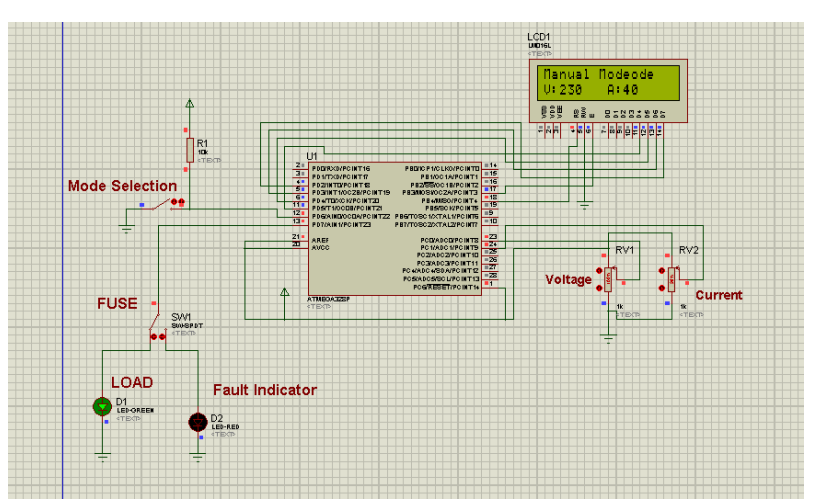

Fig (III) Output of Manual Mode 


\section{(iii).FAULT INDICATION}

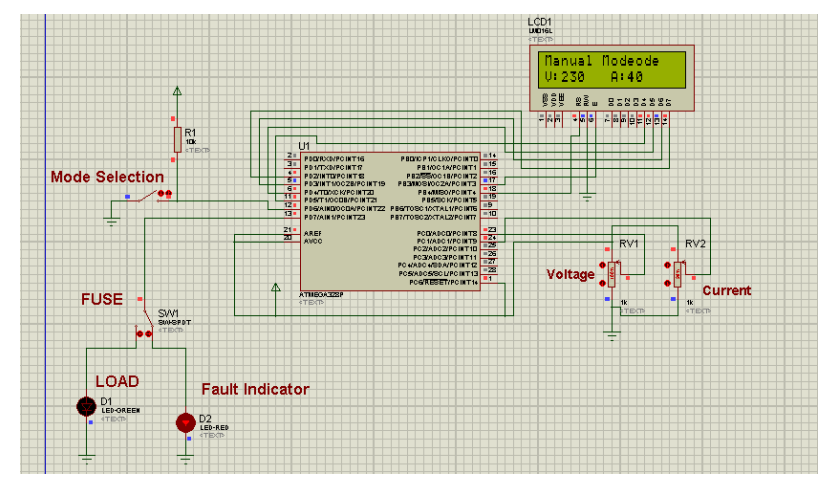

Fig (IV) Output of Fault Indication

\section{HARDWARE DESCRIPTION}

\subsection{ARUDINO ATMEGA 328}

The Arduino ATMEGA 328is a lowpower CCMOS 8-bit microcontroller based on the RISC architecture. It is low power and reasonable size.

\subsection{EEPROM}

Electrically Erasable Programmable Read Only Memory likewise utilizes MOS hardware fundamentally the same as that of EPROM. Information is put away as charge or no charge on a protected layer or a protected gliding entryway in the gadget.

\subsection{REGULATED POWER SUPPLY}

Managed control supply is an electronic circuit that is intended to give a steady DC voltage of foreordained an incentive crosswise over load terminals regardless of AC mains vacillations or load variety or in other it changes over unregulated AC into a consistent DC.

\subsection{LCD}

Many microcontroller devices are used as smart LCD to display the output in the form of visual information. This design shows connection of a Hitachi LCD display to a PIC microcontroller.

\subsection{RTC}

A Real Time Clock (RTC) is utilized to keep up the constant and information in disconnected preparing.

\subsection{RELAY CIRCUIT}

A relay is an electrically operated switch used to isolate one electrical circuit from another.

\subsection{VOLTAGE SENSOR}

The voltage is detected by utilizing a potential transformer and the acquired flag is amended at the primary operation amp stage and speaker at the second operation amp arrange.

\subsection{CURRENT SENSOR}

The current is detected from by utilizing current transformer and it is redressed at the primary operation amp stage and enhancer at the second operation amp arrange.

\section{CONCLUSION}

The main progress of this paper is persistently screen the meter perusing without human intervention and also provides efficient meter reading to avoid billing error. It has advantage i.e. maintenance cost is low. It displays billing data on LCD for client warning and bill is sent to client with due date. This meter reduces the power consumption caused in our house. It also acts as a both prepaid and postpaid meter.

\section{REFERENCES}

[1] H.G.RodneyTan, C.H.Lee,V.H.Mok, "Automatic power meter reading system which includes the lost content. And while preparing bill the system using GSM network, "the 8 conference (IPEC 2007), international power engineering.

[2] Subhashis Maitra, "Embedded Energy MeterA New concept to measure the energy consumed by a consumer and to pay the bill", power 
system technology and IEEE power india conference, 2008.

[3] Yujun Bao and Xiaoyan Jiang, "Design of electric energy meter for long-distance data information transfers which based upon GPRS", ISA 2009, International workshop on intelligent systems and applications, 2009.

[4] Xiujie Dong, Yang, You Zhou 2010 IEEE, "The design of wireless automatic meter reading system based on SOPC" in WASE international conference on information engineering.

[5] M.P.Praveen, "KSEB to imtroduce SMS based fault maintenance system", The hindu news on 2011.

[6] Soma ShekaraSreenadh Reddy Depuru, Lingefeng Eang, VijayDevabhaktuni, Electricity Theft: Overview,issues, prevention and a smart meter based approach to control theft",Energy policy, vol.39,no.2,pp.10071015,Feb.2011

[7]Nabil Mohammad, Anomadarshi Barua and Muhammad Abdullah of Arafat, "A smart prepaid energy metering system to control electricity theft", in proceedings international conference on power, Energy and control (ICPEC), vol.562, no.565, pp.668, Feb 2013.

[8] K.Ashna and Sudhish N George, "GSM based automatic energy meter reading system with instant billing in proceeding of international multi conference on automation, computing , communication, control and compressed sensing (Imac4S),VOL 65,NO.72,pp-22-23, mar 2013

[9] Elias Yaacoub, Adan Abu-Dayya, "Automatic meter reading in the smart gridusing contention based random access over the free cellular spectrum", computer networks Feb2014.

[10] Vivek kumar Sehgal,Nitesh panda,Nipun rai Handa, "Electronic energy meter with instant billing",UKAim Forth European Modelling Symposium on Computer Modelling and Simulation. 